\title{
Os superdotados na educação brasileira: o lugar do invisível
}

\author{
Cristina Ferreira Branco (MPNTDE/UniCarioca) \\ Gisely de Carvalho Gavinho do Nascimento (MPNTDE/UniCarioca) \\ Leonardo Trotta (UniCarioca - SEEDUC/RJ)
}

\section{Resumo}

Indivíduos Superdotados(SD) ou Altas Habilidades (AH) sempre se destacaram entre seus pares em todas as sociedades ao longo da História da Humanidade, suscitando diferentes práticas e abordagens em relação às suas múltiplas e fascinantes habilidades. Paralelamente, na tentativa de compreender essas mentes, foram se estruturando estudos relativos à inteligência, e uma visão multidimensional da superdotação se consolidou, embora ainda não se encontre dentro do contexto da educação brasileira um panorama favorável aos $\mathrm{SD} / \mathrm{AH}$. Assim, o objetivo geral deste estudo é analisar a situação de dois indivíduos inseridos no contexto educacional brasileiro, tomando como referencial teórico Arroyo, Martorell e Tarragó em sua análise multidimensional da superdotação, a partir do conceito de genialidade proposto por Vygotsky e da Teoria das Múltiplas Inteligências, criada por Gardner, e propondo possíveis caminhos para que a educação possa tornar visíveis esses indivíduos.

Palavras-chave: Educação Brasileira, Altas Habilidades, Eixos da Superdotação.

\begin{abstract}
Gifted individuals (SD) or High Abilities (AH) have always stood out among their peers in all societies throughout Humanity history, raising different practices and approaches in relation to their multiple and fascinating abilities. At the same time, in the attempt to understand these minds, studies related to intelligence were structured and a multidimensional vision of giftedness was consolidated, although a scenario favorable to SD I AH has not yet been found within the context of Brazilian education. Thus, the general objective of this study is to analyze the situation of two individuals inserted in the Brazilian educational context using as theoretical reference Arroyo, Martorell and Tarragó in their multidimensional analysis of the Superdotory, based on the concept of genius proposed by Vygotsky and the Theory of Multiple Intelligences, created by Gardner, and proposing possible ways in which education can make these individuals visible.
\end{abstract}

Keywords: Brazilian Education, High Abilities, Axes of Giftedness.

\section{Introdução}

Uma das questões mais instigantes e desafiadoras dentro do contexto educacional reside no trabalho com os indivíduos superdotados ou altas habilidades, em função não apenas da complexidade e da variedade de características que compõem cada um deles, tornando-os singulares em muitos aspectos, como da multiplicidade de vertentes que se voltaram para a análise desses indivíduos.

Fala-se em superdotados ou em altas habilidades, numa ideia que por muito tempo esteve associada a uma inteligência superior. Porém, o próprio conceito de inteligência foi se modificando ao longo do desenvolvimento da Psicologia, deixando de ser um conceito unidimensional, mensurável, para se transformar em um conceito multidimensional, trazendo assim uma nova perspectiva para o estudo da superdotação. (Gardner,2001) 
No entanto, apesar do progresso acima descrito, a educação brasileira não possui um trabalho consistente e contínuo voltado para as necessidades e potencialidades dos alunos superdotados, e tem-se um recorte dessa constatação na matéria publicada na revista ÉPOCA e que serve de base para este artigo.

Tentando compreender um pouco acerca das características dos indivíduos superdotados e entender o lugar deles na educação brasieira, este artigo se propõe inicialmente a traçar um breve panorama, mostrando o papel desses indivíduos nas diferentes sociedades ao longo da História. Busca-se, com isso, verificar de que forma as diferentes habilidades comuns a essas pessoas foram abordadas pela cultura em que estavam inseridas e que intervenções foram feitas de forma a integrá-los ao seu contexto.

Também traz uma breve abordagem acerca do conceito de inteligência na sua primeira acepção dentro de uma perspectiva unidimensional e com os famosos testes de inteligência que buscavam quantificar e classificar os indivíduos, identificando precocemente aqueles com inteligência superior.

Em oposição à ideia anteriormente apresentada, traz o conceito de genialidade proposto por Vygotsky (1996) e a ideia das múltiplas inteligências concebidas por Gardner (1995), estabelecendo a relação entre as ideias concebidas com as características dos meninos Dirceu e Giovanni, protagonistas da matéria publicada na revista ÉPOCA, em fevereiro de 2016.

Dentro da perspectiva das Múltiplas Inteligências, o texto apresenta a concepção de Altas Habilidades, concebido por Arroyo, Martorell e Tarragó. As autoras trazem a ideia de superdotação relacionada a três eixos: criatividade, personalidade e inteligência. Esses eixos estão relacionados a um elenco de características que possibilitam uma avaliação da superdotação dentro de uma perspectiva da multidimensionalidade da inteligência.

Sob a ótica das ideias acima, é proposto um olhar sobre Giovanni e Dirceu, nas diferentes fases de vida relatadas brevemente, numa análise pautada nos três eixos propostos, mostrando diversas características que ratificam a ideia de serem ambos indivíduos superdotados (SD) ou Altas Habilidades (AH).

A partir dessa análise que conduz à constatação de que Giovanni e Dirceu, dois indivíduos superdotados se tornaram invisíveis para uma escola que não enxerga os indivíduos em suas potencialidades, da mesma forma que não permite que eles protagonizem sua aprendizagem, são propostos alguns caminhos para que histórias como a dos meninos não continuem se repetindo, de forma cruel, pela irrelevância com que é tratada.

\section{O lugar dos superdotados na história: primeiros registros}

Ao longo da história das sociedades, os indivíduos que, de alguma forma, eram vistos como os mais capacitados para determinadas tarefas em comparação com seus pares, atraíam para si o imaginário de seu povo, sendo muitas vezes considerados seres mágicos ou mesmo divinos. (Gama, 2006)

Os registros que existem sobre esses seres datam de épocas e sociedades milenares: na Roma antes de Cristo, na Grécia e no Egito, os indivíduos superdotados tinham suas habilidades direcionadas de acordo com o interesse da cultura em que estavam inseridos. (Gama, 2006)

Sabe-se que na Grécia e em Roma os meninos aos sete anos eram selecionados e retirados do seio familiar a fim de serem educados para a arte da guerra. Também nessas sociedades, os meninos considerados superdotados tinham sua educação voltada para a arquitetura, o direito, a engenharia e a administração, embora a educação superior fosse direito apenas concedida aos homens, mostrando que o atendimento a esses indivíduos desde cedo não se deu plenamente. (Gama,2006)

Na Grécia antiga, Homero concebia a inteligência como uma entidade diferente de outras habilidades hu- 
manas, ou seja, como uma capacidade superior, como demonstraram inúmeros estudos e pesquisas que só não conseguiram definir precisamente o que é inteligência nem tampouco o conceito de superdotação. (Gama,2006)

Também existem vários registros históricos que apontam para diferentes momentos em que a questão da superdotação veio à tona, como nas propostas de Platão, que trazia a ideia de que indivíduos com inteligência superior, ou superdotados, deveriam ser selecionados logo nos primeiros anos da infância para que suas habilidades fossem direcionadas em benefício do Estado. (Gama, 2006)

Encontramos ainda, dentro das sociedades orientais, registros de uma série de exames competitivos criados pelos chineses há cerca de 2000 anos antes de Cristo, com a finalidade de selecionar crianças que se destacavam por sua inteligência superior, que passavam a receber um atendimento especial, sendo consideradas "divinas" e, por isso, encaminhadas à corte do imperador chinês, pois, segundo a sabedoria ancestral, essas crianças eram tidas como sinal de prosperidade nacional. (Kwok, sem data) Na cultura chinesa, uma prodigiosa imaginação criadora, que se manifestava por meio da poesia e de ensaios, era extremamente valorizada e, por isso, encontramos na literatura dessa sociedade vários exemplos de crianças com habilidades excepcionais nessa área, como Li Bai, famoso poeta chinês que, com apenas 5 anos, conseguiu memorizar toda a obra de Confúcio, e Quan De Yu, que com apenas 4 anos de idade começou a escrever poesia . (Kwok, sem data)

Conforme se percebe, os indivíduos superdotados eram vistos como portadores de uma inteligência superior, se comparados aos seus pares. Assim, a questão da superdotação, em sua gênese, estava ligada essencialmente à inteligência. (Gama, 2006)

De fato, a inteligência continuou sendo o alvo de inúmeras pesquisas que buscavam compreender um pouco mais a mente extraordinária dos indivíduos superdotados. Gama (2006) nos mostra que, na virada do século XX, o britânico Francis Galton e o francês Alfred Binet trouxeram uma nova perspectiva para as pesquisas nessa área. Estes estudiosos se basearam nos estudos a respeito da Origem das Espécies, de Charles Darwin (primo de Galton) acerca do desenvolvimento da inteligência humana e, com base nessas pesquisas, Galton criou um laboratório em Londres, onde aplicava testes psicológicos. (Gama,2006)

Já os estudos de Binet levaram o governo francês, em 1904, a lhe solicitar a criação de um instrumento que pudesse prever se crianças teriam sucesso nas escolas francesas. Esse instrumento, que testava as habilidades nas áreas verbal e lógica, deu origem ao primeiro teste de coeficiente intelectual (QI) desenvolvido por Lewis Terman, na Universidade de Standford, Califórnia, e que foi chamado Standford-Binet Intelligence Scale. Desta forma, "surgiu o conceito de inteligência como capacidade inata, geral e única, passível de ser testada, que permite aos indivíduos um desempenho maior ou menor, em qualquer área da atuação humana." (Gama, 2006. p.28)

Essa vertente de pensamento se manteve viva até a metade do século XX. Porém, com o passar do tempo, os chamados testes de inteligência utilizados na investigação da superdotação acabaram se tornando ineficazes, em virtude do surgimento de novas abordagens para a análise desses casos.

\section{Vygotsky e o conceito de genealidade}

Lançando uma nova luz nos estudos acerca dos superdotados, Vygotsky propôs o conceito de genialidade, publicado na Grande Enciclopédia de Medicina, editado pela Cia. Enciclopédia Soviética. Nele o autor defende que a genialidade é "um grau superior de talento que se manifesta em elevada criatividade, tendo extraordinário significado histórico para a vida da sociedade.” (Vygotsky, 1929, p.612 e 613)

Postula ainda que a genialidade pode se manifestar em diferentes setores da criatividade humana: tecnologia, ciência, arte e política, o que, de certa forma, aproxima essas ideias das proposições de Gardner acerca das Múltiplas Inteligências. (Gardner, 1995) 
Também apresenta, dentro do conceito de genialidade proposto, a ideia do pioneirismo por parte dos indivíduos considerados gênios e, nesse momento, ao se lançar o olhar sobre Dirceu e Giovanni , os protagonistas da matéria publicada na revista ÉPOCA, em fevereiro de 2016, constata-se o pioneirismo de Giovanni , ao construir um rádio, aos seis anos de idade, e sintonizar a BBC para aprender inglês, um dos idiomas em que se tornou fluente, de forma autodidata, ao criar a primeira biblioteca digital em braile do país, no $1^{\circ}$ ano da Faculdade de Pedagogia da USP.

Pensando no grande talento com os números precocemente demonstrado por Dirceu, surge uma questão: o quanto de pioneirismo aquele menino poderia ter trazido, mas que não foi visto nem pela escola, indiferente a ele, nem pela família, em sua simplicidade? Acrescente-se ainda a falta de acolhimento, em função da ausência de políticas públicas voltadas para o atendimento aos superdotados e da falta de informações sobre o assunto.

Segundo Vygotsky, a genialidade não se dá de forma efetiva em todas as áreas, mas, antes, se manifesta em algumas áreas da atividade criadora e não em outras, o que, nesse aspecto, torna as proposições de Vygotsky similares às ideias de Gardner. Dentro dessa ótica, aponta, ainda, a personalidade e a criatividade acima da média por parte dos superdotados, como características que diferenciam esses indivíduos de seus pares, o que a aproxima de Arroyo, Martorell e Tarragó, autoras que trazem a ideia da superdotação definida a partir de três eixos intrinsecamente relacionados: criatividade, personalidade e inteligência.

Para Vygotsky, não existem estudos que comprovem a genialidade como sendo hereditária. Por outro lado, aponta as condições sociais e econômicas favoráveis como determinantes para o desenvolvimento de talentos inatos como os de Giovanni e Dirceu, e isso fica patente no abismo que se abre entre os meninos com o fim do ginasial, em função das condições socioeconômicas de ambos. Dirceu, inserido num contexto social desfavorecido, acabou adormecendo seu talento à medida que precisava sobreviver à dura realidade em que vivia, enquanto Giovanni, por outro lado, favorecido por melhores condições socioeconômicas, pode ter seus talentos desenvolvidos.

Ele postula que os talentos surgem em qualquer momento e em qualquer lugar, desde que existam condições sociais favoráveis, o que reforça o que foi ressaltado anteriormente. Assim, todo talento resulta de forças sociais que o tiram do estado de latência ou o mantêm nele, como ocorre com os dois meninos.

\section{Gardner: Um novo olhar na abordagem da superdotação}

Gardner trouxe para a Psicologia a visão da inteligência numa perspectiva multidimensional e, assim, os parâmetros de identificação dos indivíduos superdotados foram se redefinindo. Seus estudos foram fundamentais para a desconstrução da ideia de que a inteligência podia ser apenas mensurada por meio de testes ou em determinadas áreas, sempre privilegiando os conhecimentos escolares.

Sua teoria postula que a inteligência deve ser entendida como "um potencial biopsicológico para processar informações, que pode ser ativado num cenário cultural para solucionar problemas ou criar produtos que sejam valorizados numa cultura." (Gardner, 2001, p.47)

Essa concepção traz uma visão inovadora da inteligência, mostrando que esta possui diferentes formas de se constituir em uma pessoa e que cada um possui diferentes inteligências e por isso diversas formas de resolver os problemas. Além disso, menciona que a inteligência sofre influência dos valores de culturas específicas e também em razão das oportunidades que forem disponibilizadas ao indivíduo.

Gardner então expõe outra maneira de ver os sujeitos e entender a mente humana, concebendo-a de forma multifacetada e pluralista. Sob essa ótica, desenvolveu a Teoria das Inteligências Múltiplas, que multidimensiona o conceito tradicional de inteligência e entende que "a capacidade de resolver problemas permite à pessoa abordar uma situação em que um objetivo deve ser atingido e localizar a rota adequada para esse objetivo. A criação de um produto cultural é crucial nessa função, na medida em que captura e transmite o conhecimento ou expressa as opiniões ou os sentimentos da pessoa" (Gardner, 1995, p. 21). 
O menino Giovanni, protagonista da matéria que serviu de base a esse estudo, graças à sua habilidade na área de eletrônica, constrói, aos seis anos, um rádio para captar o sinal da emissora londrina BBC, a fim de desenvolver a fluência na língua inglesa, primeiro dos sete idiomas em que obteve proficiência, de forma autônoma, graças à sua inteligência linguística. Seu objetivo de construir um produto que representasse as suas ideias, ou como ele concebia o rádio, acabou também atendendo a uma outa demanda do menino.

Mais tarde, já adulto, estudante e pesquisador na área de Pedagogia, criou a primeira biblioteca digital em braile, dando início ao trabalho na vertente da Educação Inclusiva. Construiu, mais uma vez, um produto que traduzia suas ideias naquele momento.

Gardner, em sua teoria, aponta que os indivíduos possuem oito inteligências, a saber: corporal-cinestésica, musical, linguística, lógico-matemática, espacial, interpessoal, intrapessoal, naturalista e a existencial. Estas inteligências, conforme postula o autor, na maioria das pessoas, funcionam combinadas, e a resolução de algumas atividades poderá envolver uma fusão de várias delas (Gardner, 1995, 2001), teoria que derruba de vez a ideia da inteligência unidimensional.

Neste sentido, indivíduos com altas habilidades destacam-se no grupo social em que estão inseridos por apresentarem uma ou mais destas "inteligências" ou habilidades, evidenciando sua capacidade superior. Tendo-se a compreensão destas habilidades, pode-se perceber que os indivíduos com altas habilidades/superdotação apresentam características que podem ser evidenciadas em comparação a um grupo e observadas pelas pessoas de seu convívio ou por ela mesmas.

Analisando os meninos Giovanni e Dirceu sob a ótica da teoria de Gardner, percebe-se, no primeiro, a combinação das inteligências linguística, que se faz patente na aprendizagem autodidata de sete idiomas, lógico-matemática e espacial; no outro, temos a inteligência lógico-matemática, que se traduz pela facilidade de realizar operações complexas, aliada a uma inteligência interpessoal, que sempre o tornava "querido por todos". (Revista ÉPOCA, fevereiro /2016).

\section{Na trilha de Gardner, Arroyo, Martorell e Tarragó}

Tendo como base a ideia da inteligência em seu sentido multidimensional, Arroyo, Martorell e Tarragó (2006) apresentam algumas ideias relacionadas às características de indivíduos portadores de Altas Habilidades (AH) ou Superdotação (SD), a partir de uma questão que se faz necessária como cerne de toda a discussão. Quem são os superdotados? E como resposta, nos apresentam os superdotados como indivíduos com um elevado potencial intelectual aliado a uma alta capacidade de produzir ideias novas e originais.

Essas autoras postulam que o conceito de superdotação se estrutura a partir de três eixos fundamentais intrinsecamente relacionados de tal forma que apenas um dos elementos constituintes isoladamente não é capaz de definir um SD /AH. São eles: inteligência, criatividade e personalidade.

Em relação à Inteligência, as autoras afirmam que o indivíduo SD/AH dispõe de um considerável potencial em pelo menos uma das áreas que compõem a inteligência humana, aliado a uma elevada capacidade para realizar tarefas criativas e um pensamento capaz de combinar esses aspectos a um resultado inovador, diferente, único.

Indivíduos com SD/AH apresentam uma grande capacidade em relação a um ou mais aspectos de inteligência ou uma considerável destreza para uma habilidade ou um comportamento específico. Apresentam ainda uma inteligência excepcional que os distingue e os destaca dentre aqueles que possuem uma inteligência considerada normal, em função de sua rapidez e facilidade que demonstram para aprender, combinar e usar os conhecimentos, de modo superior ao demonstrado por seus pares.

Giovanni, um dos protagonistas da matéria sobre superdotados que serve de base a este artigo, apresenta uma notória capacidade na área de eletrônica, trabalhando na montagem e desmontagem de rádios desde os seis anos de idade, além de ter uma considerável habilidade no aprendizado de diversas línguas, tornando-se auto- 
didata no domínio de sete idiomas, num processo iniciado aos sete anos de idade com o aprendizado do inglês necessário à leitura de livros de eletrônica.

Ao lado dele, temos Dirceu com uma excepcional capacidade para cálculos e que, aos onze anos de idade, cursando a $5^{\text {a }}$ série, mostrava pleno domínio de operações envolvendo equações de segundo grau e cálculos infinitesimais simples como derivação e integração, enquanto a professora trabalhava com equações de $1^{\circ} \mathrm{grau}$, conteúdo pertinente à série que ele cursava.

Em relação ao eixo Personalidade, Arroyo, Martorrell e Tarragó (2006) postulam que não é possível definir um padrão único em relação à personalidade dos $\mathrm{SD} / \mathrm{AH}$, já que esta se define a partir da comunhão entre a carga genética determinada e individual e as experiências vivenciadas ao longo de sua vida e que moldam essa personalidade de uma forma peculiar.

No entanto, mesmo dentro da ótica da personalidade peculiar de cada SD/AH, existem algumas características apontadas pelas autoras como sendo uma marca entre esses indivíduos: (a) apresentam um sentido moral e ético consideravelmente desenvolvido, que se traduz pela preocupação com os conceitos abstratos do bem e do mal, da justiça e injustiça, do correto e incorreto, demonstrando notória sensibilidade em relação aos problemas sociais; (b) capacidade de liderança, que se traduz no grande potencial que apresentam para exercer notória influência entre seus companheiros, sendo respeitados e reconhecidos por eles. (c) elevado perfeccionismo na execução de tarefas propostas, sobretudo se estas se encontram dentro de seu campo de interesse, o que os leva a estabelecer objetivos que atingem patamares muito elevados. (d) autoconhecimento muito aguçado, o que lhes proporciona a plena compreensão de seus processos intelectuais, bem como de suas faculdades cognitivas. (e) elevada sensibilidade diante do mundo do conhecimento, tornando esses indivíduos suscetíveis a experimentar novas sensações junto aos seus pares.

Aliadas a essas características, as autoras destacam ainda a perseverança, sensação de sentirem-se diferentes a partir da ideia que possuem de si mesmos, além de inconformismo, engenhosidade e imaginação.

Neste momento, voltamos a Giovanni e Dirceu, nossos superdotados, cujas experiências vivenciadas ao longo de sua escolaridade básica definiram caminhos diversos que acabaram por obscurecer muitas das características marcantes da personalidade dos $\mathrm{SD} / \mathrm{AH}$.

Pode-se falar da capacidade de liderança que esses meninos poderiam ter exercido desde muito cedo, mas que foi obscurecida por uma escola que se limitou a classificá-los como "alunos-problema", transformando seus questionamentos em "perguntas descabidas", quando poderiam tê-los convertido em conhecimentos a serem partilhados pelo grupo. Pode-se falar também de como essa capacidade desmoronou, quando Giovanni e Dirceu foram vistos apenas como "sabe-tudo" e "exibidos", no sentido mais pejorativo que esses termos podem adquirir, tornando-os invisíveis aos olhos de uma escola que não percebe o indivíduo em suas potencialidades.

Nesse sentido, o sistema educacional em que Giovanni e Dirceu estavam inseridos, ao torná-los invisíveis, deixou de ser para eles uma "educação para a liberdade" ou para "o homem sujeito" (Freire, 1967), produzindo um efeito devastador na vida de Dirceu que, ao se distanciar do único que não lhe via como invisível, não encontrou estímulo e sentido na lógica de um sistema ao qual se acomodou, se ausentando da escola e a abandonando quando as pressões exercidas pela realidade em que vivia foram predominantes.

Giovanni, também acomodado a esse sistema, rompeu com essa acomodação ao sair da cidade logo após a conclusão do ginasial, indo cursar o ensino técnico em eletrônica; em pouco tempo tornou-se o coordenador do curso, mesmo antes de sua conclusão, graças aos conhecimentos adquiridos de forma autônoma, na biblioteca da escola enquanto era invisível.

Nesse curso, Giovanni foi descoberto por uma multinacional que, em "uma conversa e uma olhada nos trabalhos dele" (Revista ÉPOCA, fevereiro/2016), descobriu o que um sistema educacional engessado não percebeu ao longo de quase uma dezena de anos: ali estava um superdotado. A partir daí, Giovanni, mergulhou num universo em que se tornou um ser integrado ao seu conhecimento construído longe dos bancos escolares, e, portanto, "datado" e "situado" dentro da concepção piagetiana (Piaget, 1967). Situado dentro da 
perspectiva de valorização do seu saber e datado, pois, a partir daí, começa a construir sua história, liberto de um conhecimento medíocre ao qual se submetia.

O novo caminho traçado por Giovanni trouxe-lhe a possibilidade de desenvolver sua capacidade de liderança e elevado perfeccionismo na execução das tarefas que lhe eram propostas, pelo fato de elas estarem em sua área de interesse. Num curto período de tempo, desenvolveu atividades tão diferentes como a implantação de sistemas em redes de ensino e a tradução de textos junto a bispos e ao próprio Papa, pelo seu vasto conhecimento de diferentes idiomas, adquiridos por conta própria. Também esse novo caminho, de integração plena com o seu conhecimento, permitiu a ele perceber que não seguiria o caminho como seminarista, traduzindo textos no Vaticano. Agora ele está liberto, pois não se encontra “[...] minimizado e cerceado, acomodado a ajustamentos que lhe sejam impostos, sem o direito de discuti-los [...]” (Freire, 1967, p. 42).

Ao contrário do colega de ginásio, Dirceu continuou simplesmente adaptado ao sistema. Passou a estudar em um curso técnico em contabilidade que muito pouco acrescentaria a sua imensa habilidade em realizar os cálculos mais complexos. Nessa época, como fica claro no texto "era querido por todos", o que reforça uma das características relacionadas à personalidade dos SH/AD: ser reconhecido e respeitado por seus companheiros pela notória influência exercida sobre eles. Logo depois, conseguiu um estágio num escritório de contabilidade, onde ficou por um curto espaço de tempo; acabou sendo empurrado para a linha de produção de uma fábrica de ferramentas, a maior da cidadezinha em que vivia, pela necessidade de sobreviver e manter as contas da casa após a morte do pai.

A adesão ao trabalho em uma linha de produção, de onde Dirceu saiu de forma trágica depois de 10 anos, representa a morte da engenhosidade e criatividade, características da personalidade dos SD/AH. A partir desse momento, "a vida de Dirceu se arrastava em dias, meses e anos sempre iguais" (Revista ÉPOCA, Fevereiro/2016), e toda sua extraordinária habilidade com os números "eram expressados na hora do café, em forma de brincadeira, e no trabalho quando tinha oportunidade" (Revista ÉPOCA - Fevereiro/2016). Ficou conhecido fora dos limites de sua cidade por sua reconhecida habilidade com cálculos, que a maioria das pessoas só realizava com o auxílio de uma calculadora. Porém, apesar de toda sua habilidade, continuava revestido pela mesma invisibilidade que o manteve durante sua vida de estudante, agora preso a uma linha de produção e, na concepção piagetiana, nada mais que um

[...] homem simples esmagado, diminuído e acomodado, convertido em espectador, dirigido pelo poder dos mitos que forças sociais poderosas criam para ele. Mitos que, voltando-se contra ele, o destroem e aniquilam. É o homem tragicamente assustado, temendo a convivência autêntica e até duvidando de sua possibilidade. (Piaget, 1967)

Esse homem, empurrado para o lugar comum, adormece suas possibilidades enquanto SD /AH; ele se manteve, durante toda a vida, invisível aos olhos de um sistema que, ao invés de integrá-lo às suas potencialidades, o transformou em mais uma peça, diminuída e intrincada a uma engrenagem que aniquila as individualidades.

O terceiro eixo estruturador que define o perfil do AH/SD é o da Criatividade. Dentro desse eixo, Arroyo, Martorell e Tarragó (2006) postulam que os superdotados apresentam um enorme potencial criativo, que pode ser notado pela habilidade para gerar ou inventar algo novo e original, com espírito de invenção e produção de novas ideias. Esse potencial criativo se traduz em originalidade (produção de novas ideias), fluidez (capacidade de gerar diferentes alternativas), flexibilidade (capacidade de gerar soluções diferentes diante de problemáticas diversas), pensamento independente (não se deixar dominar pelo comum e estabelecido) e, por fim, são dotados de um pensamento integrador que os torna capazes de conseguir fazer sínteses de reconhecido valor.

Na descrição desse terceiro eixo, nos debruçamos sobre Dirceu e Giovanni e chegamos à constatação de como o sistema educacional brasileiro vai pouco a pouco matando a criatividade tão marcante nos SD/AH. Giovanni, que se mostrou um leitor aos três anos de idade, ouviu da mãe, professora primária, o seguinte conselho: "não colocar o carro à frente dos bois", pois "querer saber mais do que lhe ensinavam era sinal de desassossego" e "destacar-se era errado". (Revista Época, fevereiro de 2016).

Seguindo esse conselho, o menino escondeu todo o seu potencial criativo, para se encaixar nos padrões es- 
tabelecidos pela escola. Vestiu uma máscara que o tornava apenas mais um, sufocando sua individualidade, seu pensamento independente, sua originalidade, fluidez e flexibilidade.

Mas toda a energia de um menino de sete anos, aliada a uma mente fervilhante de um indivíduo AH/SD acabaram por derrubar a máscara e destacar a individualidade de Giovanni em toda sua potência de pensamento independente, que se fez presente quando o menino foi chamado de "burro" pela professora e respondeu a essa ofensa fazendo a leitura de todos os cartazes que existiam em sua sala, mostrando que não se deixava dominar por aquele método entediante de repetir mecanicamente palavras que se iniciavam com determinadas letras.

Sua atitude libertadora, na concepção do menino de sete anos, foi lida como indisciplina por parte da professora, causando vergonha aos seus pais e ao próprio Giovanni, que, na ingenuidade de um menino, mas com a flexibilidade típica do pensamento criativo dos indivíduos, buscou outro caminho, que dentro da originalidade dos indivíduos $\mathrm{SD} / \mathrm{AH}$, mostrou-se totalmente coerente: ele seria aceito dentro da lógica daquele sistema educacional em que estava inserido, se substituísse o que sua professora chamava de bagunça, por questionamentos. Sua lógica estava correta, pois nada mais instigador do que os questionamentos de uma criança, que podem servir de mote para aulas mais criativas e interessantes.

Mais uma vez, o menino Giovanni se enganara. Seus questionamentos eram vistos pela professora como meras provocações e o processo ensino-aprendizagem se tornava uma luta pessoal pela manutenção da autoridade, constituída por um saber que se firmava muito mais pelo autoritarismo quase teocêntrico, na visão da professora, do que pela riqueza de conhecimentos trazidos por ela. E esse engano trouxe consequências ainda mais marcantes: o menino foi retirado da escola e, com a indicação da única psicóloga da cidadezinha onde morava, passou a estudar na Apae (Associação de Pais e Amigos do Excepcional).

Nessa instituição, mais uma vez, todas as características da mente criativa de Giovanni entraram em ação. O menino, agora convivendo com sua mãe, que ali atuava como professora, descobriu que deveria adotar um comportamento capaz de mantê-lo na classe de onde foi expulso: deveria "parar de fazer perguntas "descabidas" para sua idade, ideia que era sustentada por todos os adultos com os quais convivia. Porém, não tendo certeza de quais perguntas poderia fazer e necessitando ser aceito na escola para agradar aos pais, viu-se obrigado a camuflar toda a sua criatividade sob uma nova máscara que o deixava quieto e obediente. $\mathrm{Na}$ avaliação do adulto Giovanni, a partir daquele momento, o menino tornou-se um ator e um mestre na arte da invisibilidade.

Liberado da Apae e de volta à escola que o excluíra, Giovanni encontra um caminho capaz de manter sua máscara de menino comportado e também sua invisibilidade. Começa a frequentar a biblioteca da escola, onde devora os livros de eletrônica, assunto para o qual demonstra enorme habilidade. Esse caminho, está à margem da sala de aula, definida como microcélula de uma "educação" para a "domesticação", para a alienação[...]. Educação para o homem-objeto." (Freire, 1967) e que se esvazia de sentido para as mentes criativas dos SD/AH.

Também Dirceu, oriundo de uma família muito humilde e numerosa, foi rotulado por esse sistema como um "aluno-problema", "exibido" e "sabe-tudo", tornando-se invisível para fugir de uma estrutura que o repelia, empurrando-o para estar mais tempo junto de sua família.

\section{O fantasma do preconceito}

Todo o panorama descrito em relação a Giovanni e Dirceu aponta para uma realidade que aponta o preconceito em relação aos indivíduos portadores de AH/SD oriundo não apenas da escola, mas da sociedade em geral, fruto principalmente do desconhecimento que se tem sobre o tema, trazendo questões emocionais significativas para esses indivíduos. Um exemplo claro desse preconceito o menino Giovanni encontra desde cedo no seio de sua família através da fala de sua mãe, que o considera diferente e o orienta a não se destacar, pois isso era errado. 
Mais tarde, esse preconceito se transfere para o Campus da USP, quando o já adulto Giovanni, agora estudante de Pedagogia, cursando o $1^{\circ}$ ano, começou a sentir na pele o preconceito por parte de seus professores, logo que seu trabalho começou a se destacar. A partir daí, outras situações trouxeram para o brilhante aluno, talvez a lembrança dos bancos escolares em Campanha.

Agora, porém, consciente de suas habilidades e dotado de autoconhecimento muito aguçado, que lhe oportunizaram a plena compreensão de seus processos intelectuais, bem como de suas faculdades cognitivas, Giovanni, não vestiu a capa da invisibilidade. Antes, blindou-se com esse traço da personalidade dos SD/ AH e continuou o seu curso, enfrentando não só a recusa dos professores em lhe dar aula, como comentários recheados de intolerância por parte deles, aos quais respondeu dentro dos ditames da lei, movendo um processo para que pudesse concluir a sua graduação.

E Dirceu, agora adulto, onde estava nesse contexto de preconceito e discriminação? Ele continuava invisível e sem a consciência de suas extraordinárias habilidades, era mais um dentro de uma linha de produção. Não se destacava, pois segundo Mahoney (1998, p.223), não sentia sua superdotação como válida e, com isso, ganhava a "vantagem" de não sofrer a discriminação como seu amigo de ginasial.

De fato, o preconceito contra os SD /AH se constitui em uma forte barreira para a formação de uma identidade própria, contribuindo para uma representação negativa ou distorcida por parte desses indivíduos e isso se reflete na raridade de adultos que se reconhecem como $\mathrm{SD} / \mathrm{AH}$, negando essa condição, como ilustra o recado dado por Dirceu para o amigo Giovanni: "Disse que esse negócio de superdotação[...] não importa mais." (Revista ÉPOCA - fevereiro, 2016)

Esse preconceito aliado a mitos e crenças populares que surgem em torno do conceito que se tem dos indivíduos SD / AH também acabam acarretando a carência ou precariedade de atendimento para esses indivíduos ou mesmo o próprio diagnóstico. Isso pode ser constatado em relação aos meninos Dirceu e Giovanni que, ao longo da infância não receberam qualquer diagnóstico, mesmo apresentando vários "sinais" indicativos da superdotação. Ao contrário, a leitura feita em relação às patentes habilidades dos meninos esteve sempre relacionada a comentários negativos ou pejorativos que em nada contribuíram para um diagnóstico e, por conseguinte, um atendimento eficaz que desenvolvesse suas potencialidades.

Enquanto Dirceu passou toda a sua vida sem obter um diagnóstico, Giovanni só foi identificado como SD/ $\mathrm{AH}$, ao ser descoberto por uma multinacional que lhe abriu um caminho de oportunidades, explorando suas habilidades. Nesse aspecto, é importante ressaltar que as diferenças socioeconômicas também foram decisivas. Dirceu, inserido num contexto socioeconômico desfavorecido, dividindo seu dia entre uma escola que não o enxergava em suas potencialidades e o contato com uma família ocupada em sobreviver de forma digna, cresceu e, empurrado pela necessidade premente de sobreviver, trocou todas as possibilidades em relação ao seu potencial pela linha de produção, de onde saiu para se entregar à degradação completa.

Giovanni, ao contrário, inserido em um contexto mais favorável ao desenvolvimento de suas habilidades, encontrou um caminho que lhe permitiu desenvolver-se plenamente e escolher espaços de autoria, autoconhecimento e crescimento profissional, levando-o a seguir, a partir de sua experiência e do caminho percorrido pelo único amigo que o enxergou de fato por trás de sua invisibilidade, o caminho da pesquisa em Educação e a luta pelos direitos dos indivíduos SD/AH, participando da elaboração de projetos, leis e criando uma Instituição voltada para o atendimento a esses indivíduos e que, entre outros trabalhos, promove o treinamento de professores e gestores para o trabalho com SD/AH, na tentativa de evitar que outros alunos vivenciem as dores que ele, durante a infância, e seu amigo por toda a vida experimentaram. Em suas palavras, seu trabalho busca impedir que as crianças sejam punidas pelo simples fato de serem inteligentes. 


\section{Espantando o fantasma em busca da realidade}

Não existe uma fórmula pronta para espantar o fantasma do preconceito que existe contra os indivíduos $\mathrm{SD} / \mathrm{AH}$, levando-os ao caminho da visibilidade, É preciso antes de tudo que se aceitem as diferenças, reconhecendo-as como potencialidades e, para isso, o pontapé inicial está numa maior sensibilização sobre o tema e um conhecimento consistente que se construirá a partir de uma revisão nos currículos dos cursos de Pedagogia/Educação tão carentes de um enfoque do tema Altas Habilidades /Superdotação como é mostrado na própria matéria que serve de tema a esse artigo quando é mostrado o espanto de Giovanni ao se deparar com a ausência completa de qualquer tema ligado aos superdotados no curso de Pedagogia da mais importante universidade do país.

Também se faz necessária uma formação continuada dos professores de todos os segmentos de ensino e em todas as esferas, pois é a partir do olhar diferenciado deles que poderá se definir o caminho de cada aluno. Esta formação deve se dar por intermédio do incentivo a pesquisas, publicações na área, além da implementação de políticas públicas engajadas com as necessidades destes indivíduos e de seus familiares, como caminho para erradicar a discriminação, o esquecimento e a invisibilidade que os envolve.

Mas, para que tudo que for feito de concreto e efetivo pelos $\mathrm{SD} / \mathrm{AH}$ seja de fato verdadeiro, é determinante que se entendam e aceitem as particularidades desses indivíduos: conhecer a si mesmo e ao outro, despindose de quaisquer pré-conceitos, preconceitos, enxergando as diferenças não como empecilhos, mas como elementos capazes que possam restabelecer um espaço de construção, troca e interação para esses indivíduos.

Sob essa ótica, o papel da escola, como espaço de convivência com o plural, é de fundamental importância no sentido de entender a diversidade humana, apagando a ideia de normalidade e homogeneidade, impossíveis de se concretizar nesse espaço. Isso porque, enquanto os alunos $\mathrm{SD} / \mathrm{AH}$ não saírem da invisibilidade e não forem identificadas suas necessidades e potencialidades, enquanto não lhes for "permitido" se autorreconhecer e se aceitar como diferente sem qualquer sentido pejorativo que esse termo possa assumir, não se estará fazendo o bastante para esses alunos, e outros Dirceus serão produzidos.

Visão global e individualizada, aliadas a políticas consistentes e reais de inclusão que se traduzam por pesquisa, produção científica, formação continuada e mudanças de base na Educação, são os caminhos a serem seguidos em busca da visibilidade para os $\mathrm{SD} / \mathrm{AH}$.

Afinal, no mundo em que precisamos confirmar nossa humanidade biológica, adquirida ao nascer, com a humanidade construída em sociedade, a educação - função dos mais experientes para com os menos (sejam eles mais velhos ou não), como um esforço oriundo da constatação da ignorância, segundo Bruner (apud SAVATER, 2000, p. 17), tem que ser capaz de "despertar em quem a recebeu o desejo de fazer melhor com aqueles pelos quais depois será responsável.”

\section{Conclusão}

Os indivíduos Superdotados ou Altas Habilidades estão desde os primórdios da História inseridos nas diferentes sociedades. Nestas, sempre se destacaram entre seus pares por suas extraordinárias habilidades que eram diferentemente valorizadas e direcionadas, permanecendo essas mentes privilegiadas envoltas em muitas dúvidas que acabavam trazendo uma aura de mistério.

Essas mentes suscitaram diversos estudos acerca da Inteligência, que buscavam identificar precocemente novos talentos, direcionando-os no sentido de que trouxessem ideias inovadoras para a sociedade em que estavam inseridos. Muitos foram os estudiosos que se debruçaram sobre os Superdotados/Altas Habilidades, antes definidos apenas como portadores de uma inteligência superior. 
A Inteligência, antes avaliada a partir de testes que buscavam quantificar o desempenho dos alunos nas áreas relacionadas à linguagem e ao raciocínio lógico-matemático, foi sendo paulatinamente redefinida a partir da constatação de que uma quantificação simples era insuficiente para medir as múltiplas habilidades demonstradas pelos indivíduos Superdotados. Surgiram assim, novos estudos que propuseram uma visão multidimensional da Inteligência que ampliou de forma significativa o campo de estudos relacionado à superdotação.

No entanto, apesar desta nova perspectiva de estudos e de uma nova abordagem mais ampla em relação ao assunto, percebe-se que o sistema educacional brasileiro ainda está longe de oferecer condições adequadas para que os alunos Superdotados possam ser estimulados em todas as suas potencialidades. Ao contrário, esses alunos acabam sendo considerados um entrave pelos professores que não enxergam além da homogeneidade previsível que não rompe com o cotidiano planejado minuciosamente para os iguais.

A escola precisa se reavaliar, promovendo a inclusão dos indivíduos superdotados, a partir do estabelecimento de políticas sérias, contínuas e que busquem uma nova perspectiva que propiciará a esses indivíduos a visibilidade que lhes é devida. Não pode continuar produzindo novos "Dirceus" e "Giovannis", mas pessoas que consigam encontrar um espaço de reconhecimento e expansão de habilidades já dentro do espaço escolar, não precisando se tornar invisíveis, perdendo sua identidade e espontaneidade ou se escondendo atrás de máscaras que sufocam todo o seu potencial.

\section{Referências Bibliográficas}

ALENCAR, E.M.L.S.A. A identificação e o atendimento ao superdotado. Revista Psicologia, Ciência e Profissão. Volume 12, n¹, Brasília, 1992.

ARROYO, S.; MARTORELL; M.; TARRAGÓ, S. La realidad de una diferencia: los superdotados - diagnóstico, asesoramiento, atención escolar, integración social. Barcelona: Terapias Verdes, 2006.

FREIRE, Paulo. Educação como prática da liberdade. Rio de Janeiro: Editora Paz e Terra, 1967.

GAMA, M. C. S. S. Educação de superdotados: teoria e prática. São Paulo: EPU, 2006.

GARDNER, Howard. Inteligências múltiplas: a teoria na prática. Tradução Maria Adriana Veríssimo Veronese. Porto Alegre: Artmed, 1995.

.Inteligência: um conceito reformulado. Rio de Janeiro: Objetiva, 2001.

KWOK. C. (sem data). Gifted and Talented Education in China. From Ancientto Modern Times. Hong Kong: Kwok.

MAHONEY, A. In search of the gifted identity: from abstract concept to workable counselling constructs. Roeper Review. Bloomfield Hills, MI, v. 20, n. 3, p. 222-230, Feb. 1998.

OSHIMA,Y,F. O que a história de dois superdotados revela sobre o Brasil. Revista Época.

São Paulo : Editora Globo, Fevereiro,2016.

PÉREZ, S.G.P.B. Da transparência à consciência: uma evolução necessária para a inclusão do aluno com altas habilidades. In: Seminário Estadual de Inclusão de Pessoas com Altas Habilidades/Superdotados, 1.; SEMINÁRIO DE INCLUSÃO DA PESSOA COM NECESSIDADES ESPECIAIS NO MERCADO DE TRABALHO, 2.; SEMINÁRIO CAPIXABA DE EDUCAÇÃO INCLUSIVA, 6., 2002. Vitória. Anais... Vitória: UFES/Fórum Permanente de Educação Inclusiva/ABSD-ES/Fundação Ciciliano Abel de Almeida/FINDES-SENAI/ ES. 2002, CD-ROM (102-112).

SAVATER, F. O valor de educar. São Paulo: Martins Fontes, 2000.

VYGOTSKY, L.S. A Formação Social da Mente. São Paulo: Martins Fontes, 1996. 